\title{
Quando grandes projetos urbanos acontecem? Uma análise a partir do Porto Maravilha no Rio de Janeiro*
}

\author{
Betina Sarue \\ Centro de Estudos da Metrópole, Centro Brasileiro de Análise e Planejamento (CEM / \\ CEBRAP), São Paulo, SP, Brasil. (e-mail: betina.sarue@usp.br)
}

\section{INTRODUÇÃO}

$\mathrm{O}$ s grandes projetos urbanos são uma realidade no mundo. Nas últimas décadas, diversas cidades vêm promovendo transformações em sua configuração espacial e fundiária por meio desse tipo de política urbana. Alguns exemplos de intervenções que marcam o início dessa nova forma de planejamento urbano são La Défense, em Paris, a área portuária de Baltimore, o projeto Atlantic Yards em Nova Iorque, as Docklands de Londres e as intervenções na cidade de Barcelona, cujos consultores possuem um papel relevante na exportação da concepção para a América Latina e para o Brasil, em especial para o Rio de Janeiro.

Embora ainda exista uma disputa na literatura nacional e internacional em torno do que caracteriza um grande projeto urbano (Vainer, 2012; Altshuler e Luberoff, 2003; Smolka, 2004) o termo será tratado aqui como um tipo bastante específico de política urbana, que é con-

\footnotetext{
* A autora agradece a Eduardo Cesar Marques, João Sette Whitaker e Paolo Ricci pelos comentários ao longo do desenvolvimento da pesquisa e do texto, e aos pareceres da revista que contribuíram imensamente com o aperfeiçoamento do argumento proposto. Esta pesquisa foi realizada com financiamento do Conselho Nacional de Desenvolvimento Científico e Tecnológico, da Fundação de Amparo à Pesquisa do Estado de São Paulo e da Coordenação de Aperfeiçoamento de Pessoal de Nível Superior, e apoio do Centro de Estudos da Metrópole.
}

DADOS - Revista de Ciências Sociais, Rio de Janeiro, vol. 61, no3, 2018, pp. 581 a 616. 
centrada e integrada em um contínuo urbano, demanda investimentos de grande porte, flexibilização da legislação local e arranjos inovadores de articulação institucional intragovernamental e com setores privados, buscando a requalificação desses espaços, e provocando alteração no uso e no valor do solo com efeitos em escala urbana territorial e mais ampla no contexto da cidade (Sarue, 2015).

A abordagem mais corrente na literatura sobre grandes projetos urbanos trata de explicá-los a partir de dinâmicas econômicas associadas à valorização da terra urbana. Essas explicações abrangem tanto a análise da dinâmica capitalista de reprodução do capital que encontra na mercantilização da terra urbana uma oportunidade de expansão de fronteiras do mercado (Harvey, 1989), como abordagens que consideram as dinâmicas políticas locais, mas que são analisadas a partir de argumentos de cunho econômico, tais como a abordagem de regimes urbanos (Stone, 1993) e, mais especificamente no caso norte-americano, a explicação pela máquina de crescimento (Molotch, 1976).

O argumento defendido neste artigo não é contrário às explicações de cunho econômico, mas busca trazer luz à importância dos arranjos institucionais e formais instituídos para viabilizar grandes projetos urbanos que, embora tenham impacto direto na distribuição dos benefícios produzidos pelos projetos, são ainda pouco analisados pela literatura. Nesse sentido, tomamos como premissa que, para entender quando os grandes projetos urbanos acontecem, é necessário compreender o processo de valorização da terra urbana como resposta às pressões de reprodução capitalista e de competição entre cidades, conforme apontado pelo argumento econômico, mas é também necessário compreender quando (e como) são criadas as condições institucionais que estabelecem esse processo de valorização, tais como a sua regulação. Isso envolve a investigação de processos políticos e instrumentos de política urbana adotados.

Argumento, portanto, que grandes projetos urbanos acontecem quando há um processo de valorização da terra urbana - que pode estar relacionado às dinâmicas reprodutivas do capital - mas fundamentalmente quando são produzidos instrumentos e arranjos formais que desencadeiem esse processo a partir da regulamentação da terra. Daí a importância de a literatura passar a analisar como se dá essa articulação entre atores em torno dos projetos, mediados pelos instrumentos de política urbana adotados, e que resultam em arranjos formais que 
viabilizam as iniciativas e influenciam diretamente quem ganha o quê com sua implementação.

Nesse sentido, entender quando grandes projetos urbanos acontecem passa por compreender como são articulados os arranjos de entrega da política. Isso passa pelo exame da participação i) do Estado - por meio de governos centrais e locais - em cada fase da política de um grande projeto urbano e os padrões de governança instituídos a partir de sua relação com os principais atores urbanos; ii) dos capitais do urbano (Marques, 2012), cuja reprodução está diretamente associada ao ambiente urbano e de capitais de investimento nacionais e internacionais na presença de capital financeiro por meio de fundos de investimento; e iii) dos atores sociais, tais como associações e grupos de moradores que influenciam a disputa pela terra, já que esses arranjos estão também relacionados com o insulamento e a criação de canais institucionais de participação social - ou a sua ausência - a partir dos modelos instituídos. Portanto, proponho uma contribuição analítica fundamentada na importância dos arranjos institucionais e da governança estabelecida em grandes projetos urbanos tanto para o acesso às terras, como para a configuração dos arranjos formais que permitem a implementação dos projetos e seu financiamento. Essas condições evidenciam o contexto de disputa entre atores pelos benefícios produzidos pela política - inclusive o benefício da valoração do solo urbano - e impactam diretamente a governança urbana e o estudo da política nas cidades.

Logo, não se trata nem de refutar teorias estruturalistas ou de regimes ou coalizões, mas de entender a governança a partir dos arranjos formais e institucionais e seu impacto sobre a política urbana. A literatura sobre governança urbana já considera a importância desses arranjos, mas ainda é pouco aproveitada pelas análises de grandes projetos urbanos. Nesse sentido, Mike Raco (2014) mostrou como os detalhes da operação no dia a dia da construção dos Jogos Olímpicos em Londres são importantes para compreender seus impactos e inseriu a política em um debate sobre liberalismo ou governança contratual que vai além das análises recorrentes sobre o projeto Olímpico de Londres.

Thus, while there has been much focus on the politics of mega events and the neoliberal discourses of development that underpin them, the practices involved in the day-to-day management of contracts and structures is often put to one side, and presented as a mere extension of top-down development logics. This represents a surprising lacuna in 
the literature given that many of the policy outcomes associated with the Games, such as those surrounding sustainability and employment, are being implemented through a utopian top-down model of contractual management. In this respect the London Games has represented a new mode of state-led privatization in which public funds and objectives have been converted into privately run and contractually delivered programmes of action. (Raco; 2014, p. 176)

Os estudos sobre arranjos institucionais mostram que há, além de um fluxo global de ideias em torno dos grandes projetos urbanos associados à dinâmica do capital, também um processo de aprendizado da política pública no qual os desenhos de implementação e arranjos institucionais apresentam semelhanças que devem ser consideradas, como por exemplo na comparação entre os arranjos de governança do grande projeto urbano de East London e do Porto Maravilha no Rio de Janeiro.

Este artigo explora o caso do Porto Maravilha por meio de uma reconstrução histórica do projeto, que destaca os principais entraves da política desde as suas proposições iniciais, nos anos 1980, evidenciando como ao longo das diferentes etapas de sua formulação foi se constituindo um processo de encaixe institucional, para moldar um formato de governança que é central para compreender sua implementação a partir de 2009. Essa retomada histórica permite compreender o formato adotado pelo projeto atual, e, por fim, entender as suas implicações do ponto de vista da disputa entre os atores pelos benefícios produzidos pela política. O artigo mostra, a partir desse histórico, que uma abordagem político-institucional que considere detalhes da formulação e da implementação da política é importante para a análise de grandes projetos urbanos uma vez que esses elementos impactam os resultados desse tipo de política.

O artigo se estrutura da seguinte forma: além desta introdução, há mais quatro seções e as considerações finais. A primeira seção insere os grandes projetos no debate do urbano mais amplo, apresentando como a literatura se relaciona com tais projetos a partir da abordagem da economia política das cidades e da perspectiva da governança urbana. $\mathrm{Na}$ segunda seção apresento um histórico da formulação da política do Porto Maravilha à luz do debate anterior, mobilizando explicações sobre os principais entraves à política e os arranjos institucionais propostos para superá-los. A terceira é dedicada à análise do arranjo instituído pelo projeto e suas implicações na implementação. Em seguida, 
entramos no debate sobre inovação para compreender suas decorrências para a governança urbana. O artigo se encerra com algumas considerações finais que retomam a contribuição da análise do Porto Maravilha para os estudos sobre esse tipo de política urbana no debate sobre grandes projetos urbanos.

\section{Os grandes projetos no debate do urbano}

Em outubro de 2009, o Rio de Janeiro aprovava um grande projeto urbano de magnitude territorial e orçamentária sem precedentes na cidade ou no país. Do ponto de vista territorial são mais de 5 milhões de metros quadrados, com potencial adicional de construção (solo virtual) de mais 4 milhões, localizados em uma região central e histórica da cidade. Em termos de investimento, são ao menos 8 bilhões de reais, se considerarmos apenas os custos da parceria público-privada que estrutura o projeto. Mas para além da magnitude facilmente demonstrada por esses números, o projeto tem um impacto decisivo na cidade ao estabelecer um novo modelo de governança urbana com inovações da ordem da institucionalidade e do financiamento da política urbana no Brasil, inclusive com a delegação ao setor privado da execução de serviços urbanos básicos tais como saneamento, coleta de lixo, iluminação pública e gestão do tráfego.

O Porto Maravilha inseriu o Brasil em um movimento global de transformações na configuração espacial e fundiária das cidades por meio de grandes projetos de revitalização urbana. A economia política das cidades reúne um conjunto de abordagens centradas no seu papel na reestruturação produtiva e nas relações econômicas globais a partir de sua relação com Estados nacionais ou em uma rede global de cidades competindo por investimentos transnacionais, tendo a valorização da terra como insumo principal.

Essa corrente de explicações de cunho macroeconômico ganhou peso na literatura e abrange explicações pautadas pela dinâmica do capitalismo global, que encontra na valorização da terra uma nova fronteira de mercado (Harvey, 1989). A reprodução das dinâmicas capitalistas ecoaria no contexto local a partir da formação de coalizões que, embora considerem os processos locais, são explicadas a partir de um processo global de reestruturação produtiva. A teoria dos regimes urbanos (Stone, 1993) é útil ao sugerir que, para que as cidades respondam às demandas do investimento transnacional e da economia global, elas 
precisam formar coalizões com preferências endógenas que combinem interesses dos governos locais e dos investidores privados para a formulação de políticas locais. Nesse sentido, grandes projetos urbanos são abordados como uma resposta ao contexto global, refletindo uma disputa por crescimento econômico que encontra na valorização da terra um insumo central para a competitividade. Não há, no entanto, uma clareza sobre como se formam essas coalizões e em quais condições são negociadas as conformações de interesses de sua composição.

Já a abordagem da máquina de crescimento (growth machine) apresenta uma explicação focada no contexto federativo dos Estados Unidos e parte da premissa da ausência de repasses do governo central aos municípios e da sua dependência em relação à arrecadação por meio da tributação sobre a gleba urbana. Ou seja, as cidades disputam o interesse de investidores externos, tais como empresas e indústrias, inclusive promovendo flexibilização da legislação para uso do solo e promovendo grandes projetos de revitalização, a fim de promover o crescimento econômico local e o incremento na arrecadação via taxação da terra (Molotch, 1976).

Aqui cabe ressaltar que embora a busca por incrementos na arrecadação tributária do município seja parte do processo no caso do Rio de Janeiro, a premissa da ausência de repasses do governo central aos municípios, central no argumento do growth machine, não pode ser replicada no Brasil - e, em especial no Porto Maravilha, uma vez que a Caixa Econômica Federal (CEF) tem um papel central no financiamento do projeto. Além disso, o sistema federativo brasileiro conta com transferências fiscais obrigatórias e constitucionais de receitas arrecadadas pela União aos estados e municípios, e pelos estados aos municípios, reduzindo a desigualdade horizontal entre municípios. Em relação às políticas de infraestrutura e habitação, não há vinculação constitucional de gastos, de forma que os municípios têm autonomia para alocar recursos nessas áreas. No entanto, o alto valor das obras faz com que o governo federal se configure como um importante financiador dessas políticas e com isso a transferência por meio de empréstimos do Fundo de Garantia do Tempo de Serviço (FGTS), não obrigatórios, coloca em pauta questões relacionadas à capacidade do governo federal de induzir políticas, participando também do processo decisório. Ou seja, temos no Brasil um modelo de financiamento de grandes projetos urbanos que, na prática, depende em grande parte de empréstimos ou de financiamento por parte do governo federal. 
No debate brasileiro a abordagem estrutural também é recorrente e os grandes projetos urbanos são por vezes analisados a partir da concepção do planejamento estratégico que considera que a cidade estaria, assim como as empresas capitalistas, inserida em um mercado global e altamente competitivo (Vainer, 2012). A visão de que o bem-estar de seus habitantes dependeria do sucesso da cidade nessa competição global é o que justificaria a promoção do planejamento estratégico, e consequentemente dos grandes projetos urbanos. Esses seriam marcados por novas formas de relação entre Estado e capital privado, de forma que o Estado atuaria na flexibilização da regulação para promover os interesses desse capital globalizado (Vainer, 2012; Ferreira, 2003), rompendo com um planejamento urbano mais inserido no contexto dos Estados de bem-estar social, centrados nos planos diretores e políticas de zonificação.

É, no entanto, pouco presente na literatura nacional uma análise que busque compreender os principais aspectos da governança urbana das cidades, a fim de analisar os processos políticos e os formatos de políticas públicas adotados para dar forma aos grandes projetos urbanos. Nesse sentido, a análise de Marques (2016) sobre os capitais do urbano considera uma diferenciação entre o capital em geral delimitado a partir da tradição Marxista e trazido ao contexto urbano pela importância das cidades para as condições de produção e circulação da mercadoria, (Castells, 1983), do capital urbano definido como aquele que produz valor diretamente a partir da cidade, e que é composto, por exemplo, por incorporadoras, prestadoras de serviços e infraestrutura urbana. Essa abordagem é útil à análise dos grandes projetos urbanos uma vez que especifica os tipos de atores que participam das disputas em torno do projeto (Sarue, 2016). Sendo assim, é fundamental compreender a atuação de capitais associados à construção e ao mercado imobiliário uma vez que a produção de localização é um mecanismo central nos projetos de revitalização urbana pelo qual se abrem novas fronteiras ao mercado imobiliário e incorporador, a partir do investimento público em porções da cidade com potencial de valorização e sobrelucro (Hoyler, 2015). No caso do Porto Maravilha veremos ainda que além desses dois tipos de capitais tradicionalmente associados à revitalização urbana, também é central na formulação da política a atuação das empresas na prestação de serviços de infraestrutura urbana, tais como iluminação pública ou coleta de lixo.

Vemos que o debate apresentado aqui, seja pela perspectiva das dinâmicas locais ou globais, indica o acesso à terra como uma questão cen- 
tral à realização dos grandes projetos urbanos. É, portanto, necessário compreender como os diferentes formatos institucionais impactam, por exemplo, na reserva de terras para habitação social ou na dependência em relação ao mercado e à valorização dos terrenos. Em todos os casos, o momento de venda ou expropriação dos terrenos é fundamental, pois determina os atores que irão se apropriar do sobrelucro da valorização da região. Por exemplo, no Rio de Janeiro esse aspecto é central para explicar a realização do projeto em um território majoritariamente composto por terras públicas da União e que em algum momento de formulação da política seriam cedidas mediante a realização de projetos de habitação popular, mas que ao final passaram a ser utilizadas como moeda central de troca no acordo entre fundos imobiliários para aumentar o potencial de arrecadação via mercado, necessário para o pagamento da parceria público-privada (PPP) de obras e serviços na região. Dessa forma, a política de habitação social ficou em segundo plano no projeto, sendo apresentada apenas na segunda fase de mudanças, quando novos aportes foram solicitados ao financiador federal em função da crise econômica que paralisou os investimentos privados na região. Na comparação novamente com o caso londrino, há na Inglaterra um mecanismo específico para desapropriação de terras chamado CPO (Compulsory Purchase Order), que determina a venda de terras privadas para fins de desenvolvimento econômico mediante negociações individuais para a realocação dos pequenos proprietários. Ou seja, a composição dos terrenos e a distribuição de lotes também deve ser aferida para compreender o arranjo da política e o processo de negociação necessário para a sua implementação, que resultará, como vimos, em diferentes formas de distribuição do benefício produzido pelo investimento no território.

Esse aspecto mostra que, em concordância com o argumento econômico, o acesso à terra é sim um dos aspectos centrais dos grandes projetos urbanos, e por isso deve ser analisado também a partir dos arranjos institucionais e políticos que se configuram em cada caso. A proposta de uma abordagem da governança urbana busca especificar como os principais pontos da análise se configuram na dimensão institucional e local, argumentando que esses detalhes são importantes para o entendimento do processo de negociação que se dá para a viabilização das políticas, e que terá implicações diretas na sua implementação e nos seus resultados sobre a cidade.

É preciso, portanto, descrever e entender historicamente os formatos institucionais, e como a articulação dos atores define um modelo de 
governança local. O resultado dessa disputa implicará em maior ou menor recaptura dos investimentos públicos para o Estado (value capture), distribuição de riscos entre Estado e mercado, e mais ou menos participação da população nos processos, resultando a partir dessa combinação, em políticas mais ou menos redistributivas. Logo, é necessário estruturar a pesquisa com recursos para analisar a policy e a forma como o arranjo distribui benefícios, e a politics para compreender as condições políticas que levam a tais formatos.

O Porto Maravilha abrange a maior parceria-público privada do país, cujo contrato é pago com recursos oriundos da venda de solo virtual, atrelados ao uso do solo e ao direito de construir. Representa ainda a primeira experiência de concessão administrativa a um consórcio privado da prestação de serviços urbanos básicos, tais como saneamento, coleta de lixo, varrição de ruas, iluminação pública e gestão do tráfego em um território urbano que, por integrar o contrato de PPP atrelado a uma Operação Urbana Consorciada, deixa de onerar o tesouro municipal. A comercialização dos certificados de solo virtual, por sua vez, é negociada com o mercado por meio de um fundo de investimento imobiliário criado pela instituição financeira do governo federal Brasileiro, a Caixa Econômica Federal, responsável pelo aporte inicial de investimentos. Trata-se de uma operação financeira e de um arranjo institucional ousado do ponto de vista dos riscos e dos impactos para a governança da cidade que deve ser analisado para que seja possível compreender o projeto para além dos interesses iniciais apresentados até aqui. A literatura sobre governança urbana avançou nesse tipo de análise e propõe importantes marcos para o debate.

O framework de governança urbana propõe um enquadramento para a análise da interação entre os diferentes atores urbanos, mantendo uma linha teórica que busca compreender os arranjos locais em oposição à produção voltada essencialmente aos processos macroeconômicos (Brenner, 2002). O conceito de governança urbana busca extrapolar os limites das institucionalidades do Estado, e abordar a interpenetração entre Estado e setores privados nas decisões e na implementação de políticas (Le Galés, 2000) de forma a abranger diferentes estruturas nacionais e históricas e compreender os interesses em jogo e como eles se delimitam no território, considerando essa pluralidade de atores e de arenas de decisão.

Levi-Faur (2005) introduz uma divisão histórica do sistema capitalista em três ordens sendo que na primeira, no período do lassez-faire, as 
funções de steering (liderança, ideias e direcionamento) e rowing (provisão de serviços) eram privadas, exercidas pelo mercado. Na segunda ordem, com o capitalismo de welfare, o Estado assume ambas as funções em maior parte. Por fim, já no marco do capitalismo regulatório, o Estado mantém funções de steering mas delega ao mercado as funções de rowing caracterizando uma nova governança democrática em dois níveis. Assim, acontece uma delegação de poder de representantes eleitos a especialistas contratados pelo Estado que atuariam como representantes indiretos de segundo nível.

Como vimos, o caso de Londres é debatido por Raco (2014) a partir da relação entre grandes projetos urbanos e megaeventos, sugerindo que a preparação de Londres para as Olimpíadas serviu como laboratório para um novo modelo de governança de híbridos público-privados, com agências próprias responsáveis pela contratação de serviços, que implica uma redução da responsabilização em relação aos governos locais. Nesse modelo, atores privados regulam em nome do Estado e são, ao mesmo tempo, regulados por ele. Esse processo resulta em um tipo de contratualismo, no qual a governança é cada vez mais organizada por contratos vinculativos, requerendo que especialistas se organizem em redes em torno da regulação e da gestão de contratos. No contexto da realização de grandes projetos urbanos, os contratos vinculativos são produzidos de forma a reduzir riscos e garantir retornos aos investidores privados.

Por fim, a análise de Lowndes e Skelcher (1998), mais específica sobre os modelos de concessão de serviços urbanos a consórcios privados, mostra que esse tipo de parceria vem crescendo recentemente no Reino Unido no nível dos governos locais. Para os autores, esse crescimento é motivado pela dependência de recursos para serviços públicos, mas também por oferecerem uma forma de direcionamento e coordenação institucional em meio à crescente quantidade de agências, ligadas ao poder público local, responsáveis pela entrega de políticas e serviços. A questão seria, portanto, segundo os autores, uma inovação ao abordar questões que dependem de articulação entre organizações e suas barreiras institucionais. Essa bibliografia, no entanto, não localiza os arranjos a partir da questão territorial e do acesso à terra especificamente para políticas de renovação urbana.

Paralelamente, embora exista uma percepção clara na literatura sobre a dependência de grandes projetos urbanos em relação a recursos ex- 
ternos aos governos locais, uma vez que estes não dispõem dos altos montantes de investimento necessários para iniciar os projetos, a análise se restringe a evidenciar a necessidade de lobby junto aos governos centrais, em especial no caso norte-americano (Altshuler e Luberoff, 2003), e a realização de parcerias público-privadas (Fainstein, 2008).

Logo, faz falta uma interface a partir de uma bibliografia específica sobre governança e, em especial, sobre novos arranjos institucionais. Procuro combinar essas análises a seguir a partir do contexto local e nacional de implementação do projeto Porto Maravilha. Será necessário para tanto considerar os atores, arenas decisórias e a divisão de competências e de recursos entre o governo central e o governo local, o insulamento das instituições e a distribuição de competências entre Estado e mercado, a fim de desmembrar o arranjo de governança do modelo vigente, e então compreender as condições que viabilizaram a coalizão de interesses em torno do Porto Maravilha.

\section{De volta ao caso: a formulação do Porto Maravilha}

Retornando ao Porto Maravilha, cabe ressaltar que desde os anos 1980 existem projetos propondo a transformação da zona portuária do Rio: a Associação Comercial do Rio de Janeiro apresentou um projeto de revitalização para a região à época. O histórico de projetos evidencia que já havia desde então um interesse em promover a revitalização da região, cuja localização permitia um potencial de valorização da terra a ser explorado, mas ainda eram necessários encaixes institucionais para que ela fosse realizada. Sendo assim, ao longo das décadas de 1990 e 2000 diversos episódios marcam a delineação da política de revitalização da região portuária, para que apenas em outubro de 2009 fossem aprovados os principais marcos regulatórios que caracterizam o atual projeto de requalificação, passado então a ser chamado de Porto Maravilha. Veremos, portanto, que o argumento da valorização da terra e da busca por investimentos externos, incremento na arrecadação e participação das cidades na reestruturação econômica explica interesses potenciais por parte de atores relevantes para a política. No entanto, é necessário compreender os impedimentos à formatação de um arranjo que distribuísse benefícios de forma a conformar uma coalizão de interesses efetiva.

Na década de 1980 as principais iniciativas na região portuária são a criação do projeto SAGAS, que visava a preservação dos bairros Gam-

DADOS - Revista de Ciências Sociais, Rio de Janeiro, vol. 61, n 3, 2018 
boa, Santo Cristo e Saúde, e o projeto "Reciclagem urbanística", a primeira proposta de requalificação para a região apresentada pela Associação Comercial do Rio de Janeiro em 1982 e que tinha como objetivo transformar a região portuária para criação de um polo exportador (Ministério das Cidades, 2005). Esse projeto manifesta o início do interesse do mercado local na revitalização da área.

Já os anos 1990 são marcados pela organização de um Grupo de Trabalho formado em 1991 no interior do poder executivo municipal e que levou à formulação do primeiro desenho de uma Área Especial de Interesse Urbanístico da Zona Portuária através de decreto da prefeitura, em 1992. ${ }^{1}$ Naquele mesmo ano são realizados os Jogos Olímpicos de Barcelona que começou a influenciar o modelo carioca de revitalização com a chegada ao Rio de Janeiro de um grupo de consultores catalães para participar da realização do plano estratégico da cidade, por solicitação do então prefeito Cesar Maia (PMDB/PFL 1993 a 1996). É a chegada de uma ideia à cidade: revitalizar sua área portuária a partir da realização dos Jogos Olímpicos.

É realizada nessa fase uma série de seminários e conferências visando apresentar casos exemplares de projetos de revitalização de regiões portuárias, que contribuíram com o mood da revitalização, além de formar uma comunidade de especialistas que irão propor projetos, calcados em um conhecimento técnico apoiado em exemplos internacionais. Naquele período, a participação do setor privado era prevista por meio da formação do consórcio Rioporto, que seria responsável por coordenar a implementação de um programa de revitalização urbana (Ministério das Cidades, 2005).

Temos, portanto, até os anos 2000, demonstração de interesses do setor privado local e do poder público municipal na realização de um projeto de revitalização para a região. Em 1993 é aprovada a Lei Federal 8.630, conhecida como Lei de Modernização dos Portos, que introduz o arrendamento de instalações portuárias da União, ampliando o interesse da Cia de Docas e de outros órgãos federais proprietários de terrenos na região em revitalizar a região portuária para arrecadar recursos com a valorização de suas terras. Surgem, portanto, os primeiros esforços de articulação por parte de entes federais no planejamento da requalificação da região, inclusive a partir de modelos financiados pelo Banco Nacional de Desenvolvimento Econômico e Social $(\mathrm{BNDES})^{2}$. 
A tabela 1 abaixo resume as condições favoráveis e desfavoráveis para a formação de uma coalizão que tivesse condições de implementar o projeto naquele momento.

Tabela 1

Condições de Implementação nos Anos 1980-1990

\begin{tabular}{l|l}
\hline Principais atores: \\
Prefeitura e setor privado local (Associação Comercial do Rio de Janeiro) \\
\hline Condições favoráveis & Entraves \\
\hline $\begin{array}{l}\text { Interesse da Prefeitura e do setor } \\
\text { privado local }\end{array}$ & $\begin{array}{l}\text { Ausência de interesse de investidores } \\
\text { (mercado imobiliário e financeiro) e de } \\
\text { fontes de financiamento }\end{array}$ \\
\hline $\begin{array}{l}\text { Interesse de órgãos federais } \\
\text { proprietários de terras na região }\end{array}$ & $\begin{array}{l}\text { Ausência de mecanismos de } \\
\text { cooperação intragovernamental }\end{array}$ \\
\hline
\end{tabular}

Fonte: elaboração própria.

O início dos anos 2000 é marcado pela criação do Plano de Recuperação e Revitalização da Região Portuária - Porto do Rio que reúne esforços da Prefeitura do Rio em um projeto que respondesse aos principais entraves apresentados até então.

Com a reeleição de Cesar Maia (PMDB 1993 a 1996; PTB 2001 a 2004; e PFL 2005 a 2008) em 2005, o projeto incorpora o plano de construção de uma filial do Museu Guggenheim como ícone da revitalização, em uma busca por produzir localização a partir de um projeto cultural e de arquitetura icônica para a região que atraísse investimentos privados. É também no interior desse Plano que começam a ser gestados dois pilares importantes que serão recuperados no projeto Porto Maravilha, não sem importantes modificações, e que dizem respeito à busca por financiamento e à coordenação de interesses na coalizão: (i) a criação de um Fundo de Investimentos Imobiliários (FII) para a região portuária; e (ii) a criação de uma empresa mista no formato de sociedade de propósito específico (SPE) responsável pela coordenação do projeto, que nesse momento previa a participação da prefeitura, União e de um consórcio privado.

Ainda em 2002 a Secretaria Municipal de Urbanismo solicita a realização de um estudo que apresente os "marcos de referência para a viabilização de implementação de um Fundo de Investimento Imobiliário como mecanismo de estruturação do programa de revitalização da área portuária do Rio de Janeiro" (SMF, PGM, IPP/Prefeitura da Cidade do Rio de Janeiro,

DADOS - Revista de Ciências Sociais, Rio de Janeiro, vol. 61, n 3, 2018 
2003) que centralizaria os ativos imobiliários dos diferentes proprietários e, a partir da requalificação do território, os ofereceria ao setor privado para reciclagem ou reaproveitamento, nos moldes de permuta no VGV (Valor Geral de Vendas) ou renda gerada. O FII teria como vantagens, conforme o estudo apresentado, a subordinação dos ativos a um único planejamento, a simplificação das operações de valores imobiliários e mobiliários, a simplificação dos entraves previstos na lei de licitações (Lei 8.666/1993), bem como uma solução aos ativos de empresas estatais proprietárias de terrenos no local, que teriam garantidas frações de imóveis e quotas do FII.

No mesmo ano, a Secretaria Municipal de Urbanismo elabora um projeto de lei com o objetivo de criar a Empresa Municipal de Reestruturação Portuária da Cidade do Rio de Janeiro, a exemplo da Corporación Antiguo Puerto Madeiro, de Buenos Aires ${ }^{3}$. A empresa teria uma formação tripartite composta pela União, que integralizaria seu capital com terrenos; o Município do Rio de Janeiro, que contribuiria com as dívidas de terrenos da União, os terrenos do município, isenções de crédito, recursos para desapropriações, e isenção de ISS de obras e serviços na região; e a empresa ou o consórcio de empresas privadas que realizaria projetos, obras e comercialização dos imóveis após a reurbanização. A ideia era que a incorporação da mais-valia produzida pela urbanização e pelas receitas de venda dos imóveis seria partilhada entre os três sócios de acordo com o valor integralizado. Para tanto, os terrenos precisariam ser concedidos pela União à SPE para serem vendidos ao setor privado após realizada a infraestrutura no local, acumulando, portanto, valor agregado. Havia, no entanto, um problema de caixa inicial, uma vez que o modelo previa a arrecadação após a valorização fundiária que, na prática, dependia de investimento inicial da prefeitura em infraestrutura.

A partir dos principais entraves levantados no período anterior, apresento na tabela 2 as respostas apresentadas e os problemas remanescentes.

Vemos até aqui a continuidade de um projeto que tem como premissa a modernização de um território urbano desvalorizado, que aumentasse a sua atratividade ao investimento privado e, consequentemente, a arrecadação municipal. Esse projeto contava com interesse do poder público municipal e da associação comercial local, e haveria também o potencial interesse de órgãos da União, proprietários de terrenos na re- 
Tabela 2

Condições de Implementação nos Anos 2000

Principais atores: Prefeitura e governo federal (de forma desarticulada)

\begin{tabular}{l|l|l}
\hline Entraves 1980-2000 & Propostas 2000 & Entraves remanescentes \\
\hline $\begin{array}{l}\text { Ausência de interesse de } \\
\text { investidores (mercado } \\
\text { imobiliário e financeiro) }\end{array}$ & $\begin{array}{l}\text { Museu Guggenhaim } \\
\text { (produção de } \\
\text { localização); } \\
\text { modernização da } \\
\text { infraestrutura } \\
\text { Criação de um Fundo de } \\
\text { Investimentos } \\
\text { Imobiliários para a região }\end{array}$ & $\begin{array}{l}\text { Convencimento de } \\
\text { empresários da construção } \\
\text { civil e incorporadores } \\
\text { imobiliários para investimento } \\
\text { no projeto } \\
\text { Ausência de recursos iniciais } \\
\text { para investimento } \\
\text { Arquivamento do projeto } \\
\text { Guggenhaim por } \\
\text { determinação da Câmara dos } \\
\text { Vereadores }\end{array}$ \\
\hline $\begin{array}{l}\text { Ausência de mecanismos cooperação } \\
\text { intragovernamental }\end{array}$ & $\begin{array}{l}\text { Criação de uma SPE com } \\
\text { participação da } \\
\text { Prefeitura, União e setor } \\
\text { privado }\end{array}$ & $\begin{array}{l}\text { Convencimento dos órgãos da } \\
\text { União para transferência dos } \\
\text { terrenos de diversos órgãos } \\
\text { federais }\end{array}$ \\
\hline $\begin{array}{l}\text { Acordo em relação aos termos } \\
\text { para constituição da SPE }\end{array}$ \\
\hline
\end{tabular}

Fonte: elaboração própria.

gião, em aprovar um processo de revitalização que valorizasse suas terras.

No entanto, as condições institucionais do desenho proposto ainda não foram suficientes e o projeto foi novamente arquivado em 2005. Uma vez que não foram acordados os termos para a constituição de uma SPE que produzisse uma coordenação intragovernamental, o formato proposto até então ainda implicava riscos para os investidores privados ao não garantir um recurso inicial para impulsionar o processo de valorização fundiária que ativaria o seu financiamento. A operação ainda não contava com o governo federal para a cessão dos terrenos ou para assegurar os recursos para investimento inicial e o município, carente de recursos próprios de tamanha magnitude, não seria capaz de arcar com o investimento inicial necessário.

Logo, ainda que os interesses em torno do projeto estivessem colocados, o mesmo foi interrompido até que se produzisse uma apuração dos instrumentos propostos, de forma a capturar o interesse dos atores que implementariam a política no interior do governo federal e no se-

DADOS - Revista de Ciências Sociais, Rio de Janeiro, vol. 61, n 3, 2018 
tor privado, além do governo local. Esse salto é explicado com a revisão histórica do projeto, e é fundamental para entender o arranjo implementado e seus impactos em termos de governança e distribuição de benefícios entre os atores envolvidos.

De forma paralela ao projeto desenvolvido na Prefeitura, formou-se no interior do Governo Federal em meados dos anos 2000 um Grupo Interministerial da Área Portuária do Rio de Janeiro, que contava com a prospecção de novos modelos de financiamento junto à Caixa Econômica Federal e ao BNDES, no interior do Programa Nacional de Áreas Urbanas Centrais. Inicialmente, esse financiamento estava atrelado às diretrizes do Programa Nacional de Reabilitação de Áreas Urbanas Centrais ${ }^{4}$, inclusive com a previsão de recursos do FGTS para a construção de unidades habitacionais para diferentes faixas de renda ${ }^{5}$. No entanto, ainda faltava uma articulação que resolvesse a questão da transferência de terrenos da União ao Município.

Após o arquivamento do projeto municipal em 2005, esse grupo interministerial se subdivide em "temas críticos" do projeto para, com a coordenação de diferentes Ministérios e órgãos federais, debater e apresentar propostas às questões de "Habitação", "Urbanismo", "Transporte", "Projetos especiais" e "Arranjos institucionais". Esse trabalho resulta em um Acordo de Cooperação Técnica ${ }^{6}$ assinado entre Prefeitura e Governo Federal para reabilitação da região portuária, cujas principais propostas são: (i) criação de uma nova Área Especial de Interesse Urbanístico (AEIU) com a redefinição do perímetro da revitalização; (ii) disponibilização de terrenos da união; (iii) criação de uma sociedade de propósito específico (SPE) para coordenar o projeto; (iv) estudos sobre a viabilidade financeira e o envolvimento do setor privado; (v) criação de um modelo de mobilidade envolvendo o VLT (Veículo Leve sobre Trilhos); (vi) utilização de instrumentos de parceria previstos no Estatuto da Cidade, como urbanização consorciada, consórcios imobiliários e operações interligadas; e (vii) criação de fundos de investimento imobiliário (FIIs).

É também nesse período que o setor privado passa a participar formalmente das definições estruturais do projeto a partir de uma chamada pública (MIP) ${ }^{7}$ anunciada pela prefeitura do Rio em 2006 que visava receber propostas e estudos de modelagem necessários para viabilização de uma concessão ou parceria público-privada com o intuito de implementar a intervenção. Foi apresentada uma única proposta pelo con- 
sórcio Rio Vila e Mar, formado inicialmente pelas empresas Odebrecht, OAS, Carioca Engenharia e Andrade Gutierrez, e criado um novo grupo de trabalho municipal para analisá-la e apresentar um relatório final propositivo. Ao longo do processo, representantes das próprias empresas participavam das reuniões e da elaboração do arranjo proposto e publicado no Diário Oficial do Município em outubro de 2007.

Ou seja, uma vez que a proposta formulada no seio da Prefeitura municipal não produziu um desenho de política capaz de atrair os atores necessários a sua implementação, os entraves identificados passam a resolvidos a partir do estabelecimento de novas arenas de debate em torno do projeto, nas quais foram estudados modelos e propostas visando produzir um arranjo que fosse interessante tanto ao governo federal como ao setor privado. Com isso, consolida-se uma proposta de um arranjo institucional e orçamentário que congrega interesses de órgãos federais, municipais e atores privados.

De posse da Prefeitura em 2009, Eduardo Paes (PMDB) logo no início de sua gestão reúne as propostas desenvolvidas a partir do GE Interministerial e da chamada pública às empresas e encaminha ao legislativo municipal os dois projetos de lei que dão forma ao projeto Porto Maravilha: criação da Operação Urbana Consorciada da Região Portuária a partir da delimitação de uma Área Especial de Interesse Urbanístico; e criação da empresa mista designada para coordenar o projeto, a Companhia de Desenvolvimento Urbano da Região Portuária, CDURP, com participação apenas da Prefeitura (excluindo portanto a participação do governo federal e do setor privado, prevista anteriormente no modelo de sociedade de propósito específico). Os projetos de lei são encaminhados à Câmara Municipal em junho de 2009 e aprovados em outubro - com menos de quatro meses de tramitação, dado o pedido de urgência apresentado pela base do governo com justificativa atrelada à realização dos Jogos Olímpicos e inclusão do projeto no plano de legado da cidade ${ }^{8}$. Na próxima seção abordo como se dá esse arranjo instituído e coordenado pela CDURP. Cabe destacar que a participação do governo federal passa a se dar a partir do envolvimento da Caixa Econômica Federal, que garante os recursos iniciais para o projeto em um arranjo de investimento bastante complexo que envolve a cessão de terrenos da União à CDURP.

Antes de entrar na análise do projeto instituído, cabe esclarecer que a revisão histórica apresentada até aqui considera as arenas de negocia- 
Mapa 1

Área Especial de Interesse Urbanístico

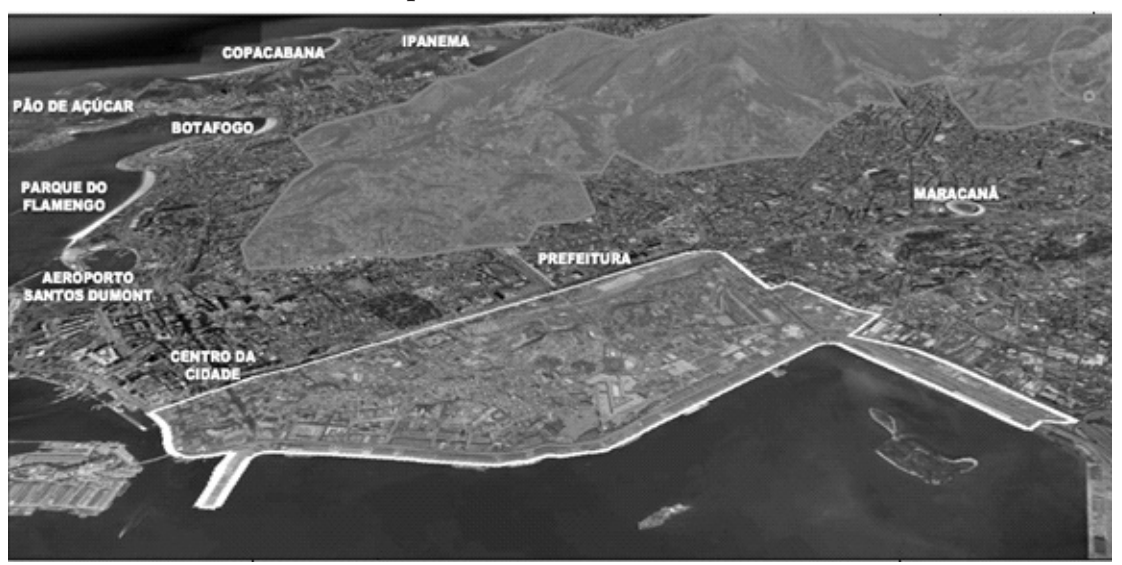

Fonte: Odebrecht.

ção formais que envolveram a formulação da política, com informações obtidas a partir de entrevistas com gestores dos principais órgãos públicos e privados, solicitações de informação via lei de acesso à informação e análise de documentos oficiais. No entanto, ainda que não seja esse o foco da pesquisa, é importante considerar que as decisões em políticas públicas são passíveis de influência por processos ilícitos. As investigações públicas divulgadas pela imprensa, em especial a partir da Operação Lava Jato, apontam um suposto pagamento de propina ao ex-deputado federal Eduardo Cunha por parte das empreiteiras envolvidas nas obras do projeto para a liberação de recursos da Caixa Econômica Federal ${ }^{9}$. Esta pesquisa considera então a existência de investigações em torno de um suposto mecanismo ilícito, mas não pretende aprofundar o debate sobre corrupção; o objetivo aqui será analisar o que acontece uma vez tomadas as decisões, entendendo que a política pública não se restringe a esse momento e que, mesmo considerando que decisões sejam tomadas por influência de processos ilícitos, é fundamental entender o contexto de encaixe institucional em que tais processos estão inseridos, como parte de um processo histórico de formulação e implementação da política pública, que define um arranjo formal para sua implementação.

\section{Entendendo o arranjo instituído}

O modelo implementado no Porto Maravilha se estrutura a partir de três pilares: o primeiro é a criação da Operação Urbana Consorciada 
(OUC) para a região portuária do Rio. Principal fonte de recursos do projeto, a OUC delimita uma área especial de interesse urbanístico, e autoriza a emissão de 4 milhões de metros quadrados de solos virtuais, chamados de CEPAC. Os Certificados de Potencial Adicional de Construção - CEPAC - garantem aos investidores incorporadores o direito de construir empreendimentos acima do padrão edilício definido para a região, e estes são vendidos pela Comissão de Valores Mobiliários $(\mathrm{CVM})^{10}$. No caso do Porto Maravilha, esses recursos estão atrelados a uma PPP que envolve a prestação de serviços urbanos em concessão administrativa (saneamento, coleta de lixo, iluminação, gestão do tráfego, entre outros) e a realização de grandes obras viárias (tais como construção de túneis, requalificação de vias e demolição da Avenida Perimetral), de infraestrutura (como redes de esgoto e abastecimento de água), implantação de mobiliário urbano e a construção de um museu. Para gerir os recursos e coordenar as obras, foi criada a Companhia de Desenvolvimento da Região Portuária (CDURP). A PPP é firmada entre a CDURP e o Consórcio Porto Novo, composto pelas mesmas empresas que participaram da formulação do projeto (Odebrecht, OAS e Carioca).

Por fim, o terceiro pilar fundamental para compreender o arranjo está na criação de fundos de investimento imobiliário. Diferentemente do que ocorre nas demais OUCs, o Porto Maravilha inovou ao disponibilizar o total de CEPACs em um único leilão, que foi arrematado pela CEF por meio do investimento de recursos do FGTS ${ }^{11}$. Com essa operação, foram criados dois fundos de investimento imobiliário (FIIs), um da CEF e outro da CDURP, como forma de transferência de recursos entre as instituições. A CEF, através de seu FII, passou a ser detentora do total de CEPACs e a negociá-los diretamente com o mercado, sem a necessidade de leilões e sem o pré-estabelecimento de lotes residenciais ou comerciais. Com isso, passa a controlar o processo de especulação sobre os usos dos empreendimentos na região. Ao mesmo tempo, adquiriu o direito prioritário de compra dos terrenos correspondentes ao uso de $60 \%$ dos CEPACs por meio de uma operação denominada Prêmio por Opção de Compra ${ }^{12}$, e passou a ter controle sobre o tempo de venda ou comercialização dos terrenos junto ao mercado, podendo se beneficiar do tempo de valorização da operação. Por outro lado, o Fundo se compromete com o pagamento do valor total da PPP ao longo de 15 anos.

Essa questão temporal é central, pois responde ao debate colocado no projeto formulado no início dos anos 2000, quando a criação de fundos

DADOS - Revista de Ciências Sociais, Rio de Janeiro, vol. 61, n 3, 2018 
de investimento imobiliário e de uma sociedade de propósito específico previa justamente que os terrenos fossem comercializados no mercado após o processo de valorização imobiliária consequente do investimento público na região. Logo, a sociedade de propósito específico, que previa então a participação da União, prefeitura e investidores privados, capturaria o sobrelucro produzido pelo investimento público. No entanto, um entrave à época estava justamente na ausência de recursos para dar início a esse processo de valorização. Já no modelo instituído não há uma sociedade entre União e Prefeitura, e o banco federal, ao aportar os recursos iniciais previstos e assumir o controle do fundo de investimento imobiliário, captura para si o potencial de valorização, negociando diretamente com o mercado e possuindo controle em relação ao tempo de venda de terrenos e CEPACs. No entanto, o aporte inicial oferecido pelo banco não é suficiente para pagar os serviços previstos no contrato de PPP ao longo de 15 anos e a capacidade de pagamento da operação passa a depender justamente dessa relação com o mercado, tornando o projeto volátil, com um fluxo de caixa arriscado, e dependente do crescimento imobiliário na região. Essa dependência, por um lado, produzirá importantes consequências para os resultados da política, especialmente em relação ao espaço dado a políticas de habitação social, mas por outro lado cria um cenário no qual os investidores privados passam a compartilhar dos mesmos interesses que o financiador da política, reduzindo com isso riscos previstos anteriormente em relação a reformulações futuras. Além disso, o banco negocia terrenos e CEPACs em formatos de permutas que criam na prática sociedades entre financiador público e investidor privado, nas quais o sobrelucro da valorização passa a ser dividido com os atores privados. A figura 1 a seguir resume essa complexa operação:

Para o funcionamento do modelo são chave a composição da propriedade da terra e tamanho dos lotes e a criação de um mecanismo de transferência dos terrenos. O tamanho dos lotes implica na facilidade e agilidade do acesso pelo mercado, de forma que se concentram as negociações em grandes lotes que consomem grandes quantidades de solo virtual, ou CEPACs. É ilustrativo que 7 grandes lotes, denominados "terrenos prioritários" equivalem ao uso de $60 \%$ dos CEPACs disponíveis. Esses são os terrenos cuja venda é priorizada à CEF, e que foram avaliados com um potencial de receita de 25 bilhões de reais (VGV). Com isso, foi criado um mecanismo de transferência dos terrenos que pertenciam a órgãos da União, que como vimos que nos anos 2000, foi um dos principais entraves ao projeto, uma vez que a venda 
Figura 1

Arranjo Institucional

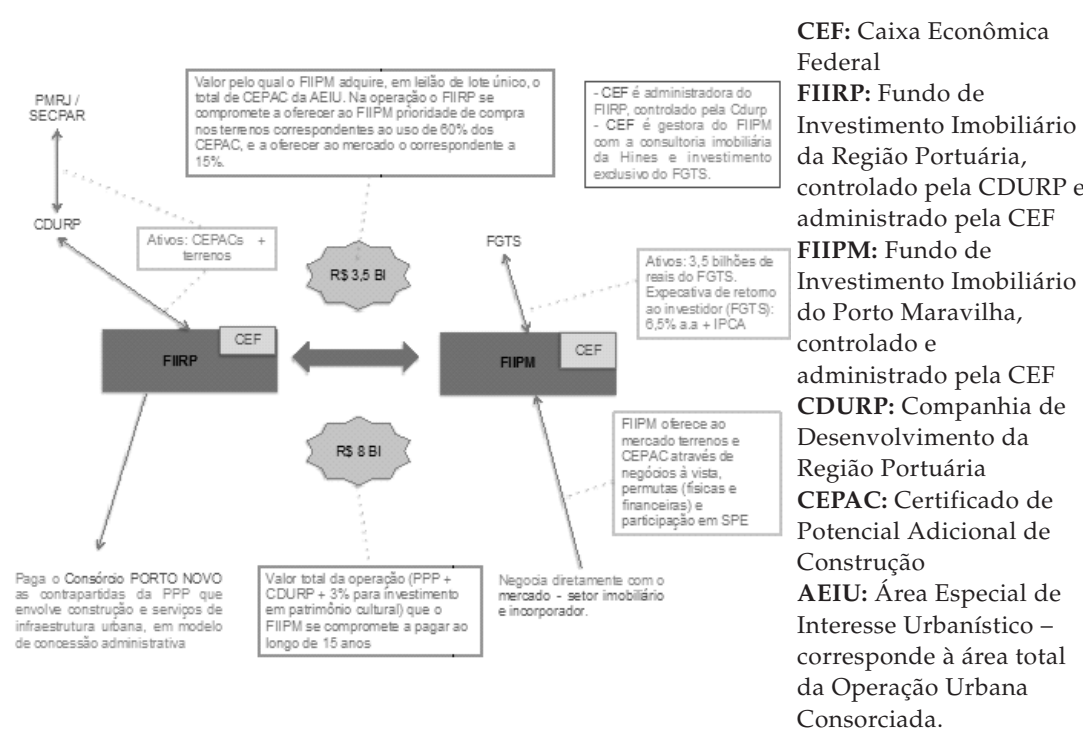

Fonte: Sarue, 2015

prioritária à Caixa Econômica Federal estabeleceu um mecanismo de retorno ao banco federal do sobrelucro produzido pelos terrenos transferidos ao município do Rio.

Uma última, porém não menos importante, análise que deve ser feita é em relação ao grau de insulamento das burocracias envolvidas na implementação do projeto e à baixa participação da sociedade e de grupos atingidos pela política. Existe, nesse arranjo, um enfraquecimento dos mecanismos de controle devido a dois motivos: i) o insulamento dos processos decisórios, afastando o Estado da interface com a sociedade e, portanto, prejudicando mecanismos de controle social (Peruzzotti e Smulovitz, 2006); e ii) o enfraquecimento de mecanismos de controle horizontal internos ao Estado (Gurza Lavalle e Isunza Vera, 2010) a partir da concessão de mecanismos regulatórios a entes privados ou mistos.

Nesse sentido, as principais decisões são tomadas no âmbito privado do fundo de investimento imobiliário gerido pela Caixa Econômica Federal que, dado o arranjo produzido, tem poder de decisão sobre o tipo de empreendimento a ser desenvolvido na região. Em relação à infraestrutura urbana e à provisão dos serviços, decisões são tomadas no 
âmbito da PPP entre a CDURP e o Consórcio Porto Novo e são, portanto, deslocadas da Prefeitura para uma empresa mista e um consórcio privado.

A questão do insulamento está diretamente relacionada à divisão de papeis entre Estado e mercado e há pouca clareza na definição de quem tem poder sobre o quê, além de diversos momentos de redução do controle público sobre o resultado final da política seja porque as decisões passam a ser insuladas da própria prefeitura, seja pelo estabelecimento de relações nas quais as empresas passam a ser sócias de seus entes reguladores - como é o caso da CDURP em relação ao consórcio executor da PPP e da Caixa Econômica Federal em relação às empresas privadas que investem nos empreendimentos imobiliários da região. Há, portanto, um processo de delegação de decisões a órgãos ou agências que não são eleitas ou vinculadas a cargos eletivos.

Esse tipo de prática, embora seja novidade no Brasil, está sendo implementado em outras cidades do mundo. Nesse sentido, cabe retomar aqui a análise sobre o impacto de novos modelos de governança na definição de quem tem poder sobre o quê, apresentada por Levi-Faur (2005) em relação à implementação de políticas por agentes não eleitos, e, portanto, mais insulados em relação aos receptores e usuários; e de Raco (2014), em sua consideração a respeito da fragilidade da regulamentação nesse modelo, de forma que a lógica de mercado prevalece sobre demandas e necessidades locais. "In other words, commercial contractualism and regulatory capitalism prevent states from targeting their spending to where elected representatives and publics believe it should be spent" (RACO, 2014, p. 192).

Segundo o autor, esse tipo de arranjo torna mais difícil a identificação do lócus do poder e da tomada de decisões, reduzindo as possibilidades de responsividade da população e de riscos atrelados à resistência ao projeto. Ou seja, opera em uma lógica de mitigação de riscos na qual as próprias demandas políticas se tornam algo a ser gerido. Ao mesmo tempo, as condições contratuais garantem que os projetos sejam locked in, prevenindo mudanças significativas ao longo da sua implementação. Todas essas condições têm implicações sobre a governança das políticas urbanas e impactam na cidade em termos de projeto de cidade e de oferecimento de serviços.

Além de distanciar o cidadão, usuário do serviço, da interface pública, o contrato da PPP do Porto Maravilha estabelece a forma como será in- 
vestido todo o recurso arrecadado pela venda de solo virtual na região, tirando do controle social qualquer possibilidade de intervenção, como previsto pelo instrumento das Operações Urbanas Consorciadas através da criação de conselhos. Além disso, assim como a criação da CDURP, o contrato de PPP resguarda os riscos políticos do projeto atrelados a eventuais trocas de gestão no governo local. Essas salvaguardas reduzem a percepção de riscos por parte dos investidores privados, e aumentam a atratividade do projeto. Um exemplo que ilustra esse isolamento se dá em relação ao fluxo de recursos da operação, de forma que os recursos arrecadados pela venda de solo virtual não são apenas "carimbados"; eles não devem alcançar a estrutura orçamentária da prefeitura.

Por fim, em relação ao Fundo de Investimento Imobiliário, o insulamento faz com que a decisão sobre a venda ou permuta de CEPAC passe a ser de competência do comitê gestor do fundo imobiliário, excluindo-se do processo a Prefeitura e a própria CDURP, que não possui poder de decisão formal sobre a natureza dos empreendimentos (desde que esses atendam aos parâmetros estabelecidos pela lei de criação da OUC do Porto do Rio, e sejam aprovados nos trâmites da prefeitura, por meio da Secretaria Municipal de Urbanismo). Uma implicação direta desse arranjo diz respeito à produção de empreendimentos de uso residencial ou comercial, uma vez que, no limite, o fundo poderia optar por construir apenas shoppings centers ou centros comerciais na região, retirando do projeto qualquer vinculação a políticas habitacionais.

Na próxima seção, retomo o argumento da inovação institucional do projeto e as suas consequências para a governança urbana, inclusive em relação à participação social.

\section{O argumento da inovação e as implicações à governança urbana}

$\mathrm{O}$ arranjo formulado responde, portanto, aos principais entraves ao projeto apresentados até então uma vez que: i) estabelece um mecanismo de coordenação intragovernamental que responde aos interesses do município e do governo federal; e ii) cria diversas condições de atratividade ao investidor privado, que passa a se interessar pelo projeto; iii) estabelece a fonte de recursos iniciais para investimento.

A favor do argumento, explicitamos que não houve alteração do ponto de vista do território ou da agenda de valorização da terra que explique o interesse do setor privado no projeto apenas a partir da segunda 
metade dos anos 2000: a região portuária manteve as suas características de espaço central da cidade, subvalorizado e, portanto, com potencial de valorização imobiliária, mas que sem garantias de investimento público para melhoria da infraestrutura apresentava riscos ao investidor privado. Logo, uma proposta de governança distinta faz com que essa mesma região passe a ser atrativa para investidores privados.

De forma similar, do ponto de vista do governo federal, o interesse em revitalizar a região está posto desde pelo menos a segunda metade da década de 1990 quando a aprovação da Lei de Modernização dos Portos introduz o arrendamento de instalações portuárias mobilizando o interesse em especial da Cia de Docas, mas também de outros Ministérios e Autarquias federais proprietários de terrenos na região, pela possibilidade de um novo aproveitamento dos terrenos esvaziados. Cabe ressaltar uma vez mais que, embora existam oportunidades relacionadas ao momento histórico, de alinhamento de partidos, realização dos Jogos Olímpicos e crescimento econômico ${ }^{13}$, para além do interesse de valorização dos terrenos, o interesse político do governo federal no projeto está colocado desde o início do governo Lula, e ainda assim foi apenas no final de seu segundo mandato que o projeto passou a ser implementado, criando incentivos ao repasse de terrenos.

Por fim, à Prefeitura do Rio está claro o interesse na revitalização da região desde pelo menos os anos 1980, corroborando a hipótese do papel das cidades na disputa por investimentos externos apresentada no início do texto.

Existe, portanto, uma conformação de interesses formando uma coalizão em torno do projeto que é explicada se olharmos para a governança proposta pelo arranjo institucional e orçamentário do Porto Maravilha. É possível compreender como cada um dos principais atores envolvidos na política articula seus interesses em torno dos benefícios produzidos pela política. A tabela 3 resume esse processo, retomando os entraves já apresentados.

Com isso, retomo aqui o argumento de que é necessário compreender as inovações do arranjo institucional proposto e suas implicações ao modelo de governança instituído. A análise desse desenho indica algumas condições de implementação do projeto que são resultado da disputa entre os principais atores descritos, em espaços de decisões que variam ao longo da formulação e da implementação da política. 
Tabela 3

Condições de Implementação do Projeto Porto Maravilha

Principais atores: Prefeitura, Governo Federal (por meio de um Grupo Executivo Interministerial), Caixa Econômica Federal e empresas de grande porte do setor de incorporação e imobiliário.

\begin{tabular}{|c|c|c|}
\hline Entraves 1980-2000 & $\begin{array}{l}\text { Entraves } \\
\text { remanescentes no } \\
\text { projeto dos anos } 2000\end{array}$ & Propostas do Porto Maravilha \\
\hline $\begin{array}{l}\text { Ausência de interesse } \\
\text { de investidores } \\
\text { (mercado imobiliário } \\
\text { e financeiro). }\end{array}$ & $\begin{array}{l}\text { Convencimento de } \\
\text { empresários da } \\
\text { construção civil e } \\
\text { incorporadores } \\
\text { imobiliários para } \\
\text { investimento no projeto } \\
\text { e ausência de recursos } \\
\text { iniciais para } \\
\text { investimento. }\end{array}$ & $\begin{array}{l}\text { Participação do setor privado na } \\
\text { formulação do projeto } \\
\text { Inclusão na PPP de obras e serviços em } \\
\text { concessão administrativa, - que, além da } \\
\text { garantia de contrato, sinaliza e garante } \\
\text { a execução das intervenções urbanísticas e } \\
\text { infraestruturais na região que são } \\
\text { determinantes do processo de valorização } \\
\text { fundiária, e, portanto, da expectativa de } \\
\text { retorno desses investimentos } \\
\text { Insulamento burocrático, que reduz o } \\
\text { risco do projeto devido a resistências } \\
\text { diversas ou à troca de gestão } \\
\text { Arranjo com a Caixa Economica Federal, } \\
\text { que além de resolver o problema do } \\
\text { acesso às terras (explicitado no item } \\
\text { abaixo), garante a fonte de recursos } \\
\text { iniciais para promover a valorização da } \\
\text { região e atrair o mercado imobiliário e } \\
\text { incorporador }\end{array}$ \\
\hline $\begin{array}{l}\text { Ausência de um } \\
\text { mecanismo de } \\
\text { cooperação } \\
\text { intragovernamental }\end{array}$ & $\begin{array}{l}\text { Transferência dos terre- } \\
\text { nos de diversos órgãos } \\
\text { federais } \\
\text { Acordo em relação aos } \\
\text { termos para constituição } \\
\text { da SPE }\end{array}$ & $\begin{array}{l}\text { Mecanismo de leilão de lote único garante } \\
\text { que a Caixa Econômica Federal recupere o } \\
\text { potencial de valorização de terrenos da } \\
\text { União, cedidos à Prefeitura. Ou seja, a } \\
\text { Prefeitura abre mão da arrecadação por } \\
\text { meio da valorização dos CEPACs ao } \\
\text { vendê-los em lote único à Caixa } \\
\text { Econômica Federal antes de iniciado o } \\
\text { processo de valorização imobiliária na } \\
\text { região. Por outro lado, realiza as grandes } \\
\text { obras de alta visibilidade política em meio } \\
\text { a um discurso de ausência de recursos } \\
\text { públicos. O projeto prevê ainda uma } \\
\text { expectativa de aumento substantivo na } \\
\text { arrecadação da Prefeitura de IPTU e ISS } \\
\text { em médio prazo, com a previsão dos } \\
\text { novos usos no território }\end{array}$ \\
\hline
\end{tabular}

Fonte: elaboração própria.

Durante as etapas de formulação da política, os principais espaços de decisão se deram em governos locais e no governo federal de forma quase independente, e nos quais foram formuladas soluções para os 
principais entraves do projeto descritos anteriormente. Em ambos os casos, as arenas decisórias eram insuladas de participação social ou de consultas à população impactada pelo projeto, embora o setor privado tenha sido convidado a contribuir diretamente na formulação do arranjo instituído. Embora o projeto tenha passado por diversas mudanças, as alterações se dão no âmbito dos instrumentos de política pública, mas não houve alteração em relação à proposta de produzir a revitalização da região a partir de valorização fundiária, sendo que a produção de habitação social, embora considerada em um determinado momento, nunca esteve no centro do projeto.

Já em relação à implementação, cabe destacar que há novamente um insulamento em relação à participação social tanto do ponto de vista do controle vertical como em relação à existência de canais efetivos de participação ${ }^{14}$. A operação é altamente dependente do mercado pois está ancorada na valorização imobiliária, inclusive para o pagamento de serviços de infraestrutura urbana básicos, como saneamento, coleta de lixo e iluminação que, uma vez insulados da Prefeitura, também passam a ter fraco controle social em um modelo de governança contratualista similar àquele debatido por Raco (2014) para o caso londrino. Também de maneira similar ao caso britânico, o arranjo institui mecanismos de regulação e controle público enfraquecidos por um modelo híbrido público-privado. A figura 2 resume os principais instrumentos adotados e seus impactos na governança do projeto.

A ausência de instrumentos efetivos de controle e participação social e a dependência em relação ao mercado implicam, por fim, uma ausência de incentivos à promoção de habitação de interesse social, que não está vinculada contratualmente no projeto. Além disso, a priorização de investimentos desconsidera as demandas da população impactada pelo projeto.

Embora não seja o objetivo deste artigo analisar a situação atual do projeto, cabe ao menos sinalizar que a dependência em relação ao mercado explica em grande parte a situação crítica do projeto após a realização dos Jogos Olímpicos, que culminou inclusive na interrupção dos serviços prestados pela PPP na região devido à falta de pagamento ao consórcio. Isso porque a crise econômica afetou diretamente os investimentos imobiliários, de forma que o Fundo de Investimento Imobiliário gerido pela Caixa Econômica Federal não tivesse liquidez para re- 
Figura 2

Principais Instrumentos Adotados

\begin{tabular}{|c|c|}
\hline Operação urbana consorciada & PPP de obras e serviços \\
\hline $\begin{array}{l}\text { - Comercialização de solo virtual - a } \\
\text { emissão de CEPACs permite potencial } \\
\text { de arrecadação para a Prefeitura. } \\
\text { Atrelado ao leilão de lote único } \\
\text { garante a fonte de recursos iniciais } \\
\text { para dar início a processo de } \\
\text { valorização da terra. }\end{array}$ & $\begin{array}{l}\text { - Contratualiza o compromisso de } \\
\text { investimento na região, aumentando } \\
\text { a atratividade ao mercado } \\
\text { (imobiliário, de infraestrutura e } \\
\text { serviços). } \\
\text { - Insulamento em relação à prestação } \\
\text { de serviços municipais - concedidos à } \\
\text { concessionária privada. }\end{array}$ \\
\hline Fundo de investimento imobiliário & Empresa mista municipal \\
\hline $\begin{array}{l}\text { - Garante recursos para pagamento da } \\
\text { PPP insulados da administração } \\
\text { direta, portanto, reduzindo riscos ao } \\
\text { investidor privado de interrupção por } \\
\text { troca de gestão. } \\
\text { - o controle por parte do banco } \\
\text { público federal apoia o processo de } \\
\text { transferência de terrenos da União. }\end{array}$ & $\begin{array}{l}\text { - Insulamento em relação à } \\
\text { administração direta - reduz riscos } \\
\text { políticos do projeto e atribui caráter } \\
\text { técnico. } \\
\text { - Redução de processos burocráticos } \\
\text { na coordenação do projeto, dando } \\
\text { celeridade. }\end{array}$ \\
\hline
\end{tabular}

Fonte: elaboração própria

passar recursos à CDURP para o pagamento das contraprestações do parceiro privado.

\section{CONSIDERAÇÕES FINAIS}

A maior parte da literatura busca compreender quando os grandes projetos urbanos acontecem a partir de sua inserção nas dinâmicas do capitalismo global e na difusão de ideias entre cidades, considerando um fluxo global entre os megaprojetos e suas semelhanças em termos urbanísticos. Neste artigo, argumento que, para entender quando esses projetos são de fato implementados e estruturados enquanto política, é importante uma análise complementar que considere a trajetória local e o arranjo institucional de cada projeto, bem como seus impactos na governança urbana. Ou seja, para entender quando um grande projeto urbano acontece é necessário entender como a dinâmica econômica mais ampla aterrissa em condições específicas da política, quais os detalhes do arranjo institucional a colocam de pé e como se dá a dispu- 
ta entre atores pela apropriação dos benefícios produzidos por ela. Esse tipo de análise, embora pouco presente na literatura, contribui para o entendimento dos processos que levam à realização de projetos, além de abrir caminho para a análise de seus resultados sobre a cidade e a governança urbana.

Nesse sentido, o Porto Maravilha apresenta um arranjo institucional e orçamentário complexo que passou por um longo período de formulação até se instituir a partir de instrumentos inovadores. O caso mostra que o projeto acontece apenas quando há um processo de encaixe institucional que inclui um modelo inovador de política urbana. A utilização da venda de solo virtual como principal instrumento de financiamento atrelada à criação de fundos de investimento imobiliário com aporte inicial de um banco público federal em contrapartida à cessão de terras da União, a criação de uma empresa mista para coordenação da política, a contratualização dos investimentos em uma PPP de obras e serviços e a duração de 15 anos estabelecem um modelo de política urbana que agrega interesses dos principais atores envolvidos, formando uma coalizão de apoio ao projeto.

O caso evidencia, portanto, a importância de analisar o desenho institucional do grande projeto urbano para compreender as condições de sua realização e seu impacto sobre a governança urbana, trazendo luz a variáveis institucionais e políticas, além das condições econômicas amplamente debatidas pela literatura. Com isso, destaca questões fundamentais para que estudos de grandes projetos urbanos abordem a realização de tais projetos, tais como o insulamento, a divisão de riscos e oportunidades e a responsabilidade de regulamentação e os impactos do arranjo sobre a governança urbana. A complexidade dos arranjos requer análises de atores e espaços decisórios que, aliadas aos contextos locais, permitam um entendimento sobre os múltiplos interesses em jogo e sobre o desenrolar da política.

A literatura sobre grandes projetos urbanos tem a ganhar com as contribuições oriundas dos estudos de governança urbana, em especial sobre novos arranjos institucionais. O debate sobre a divisão de tarefas entre mercado e Estado no marco desses modelos, bem como a composição múltipla de atores e de arenas decisórias e as análises sobre participação social nos projetos são pontos fundamentais que poderão se desdobrar em novas agendas de pesquisa, a fim de compreender os impactos dos diferentes arranjos nos resultados da política. Essas condi- 
ções, ao contrário de isoladas dos marcos econômicos, oferecem ferramentas para compreender a forma como se organiza a disputa entre atores em torno da captura do processo de valorização da terra, que são imprescindíveis para o debate sobre o caráter redistributivo ou concentrador desses projetos como uma agenda de pesquisa futura à literatura especializada.

Recebido para publicação em 3 de agosto de 2017

Reapresentado em 6 de abril de 2018

Aprovado para publicação em 15 de outubro de 2018 


\section{NOTAS}

1. Apresentados no Relatório Básico da Área de Especial Interesse Urbanístico da Zona Portuária do Rio de Janeiro, produzido pela Superintendência de Planos Locais da Secretaria Municipal Urbanismo.

2. O projeto "Bonde no Centro" consiste em um estudo apoiado pelo BNDES prevendo a criação de um sistema de veículos sobre trilhos na região central, e que seria posteriormente recuperado com o VLT da região portuária. Em 1995 o Ministério de Transporte e a Companhia Docas do Rio de Janeiro realizam o "Seminário Nacional de Revitalização de Áreas Portuárias - Projeto Rio de Janeiro" que criou um Fórum de Debates sobre o projeto de revitalização da Zona Portuária a partir do arrendamento do Píer Mauá, e do REVAP - Programa Nacional de Revitalização de Áreas Portuárias -, desenvolvido pelo Ministério dos Transportes. O Seminário também foi marcado pela declaração de interesse em financiar projetos de revitalização na zona portuária do Rio de Janeiro pelo BNDES e pela ABRAPP - Associação Brasileira de Entidades Fechadas de Previdência Privada.

3. Segundo o próprio secretário, a Corporación Antiguo Puerto Madeiro era uma empresa pública, mas com dinâmica de funcionamento privado, e que recebeu do governo central argentino os terrenos do antigo porto, promoveu a venda dos terrenos em leilão e aplicou os recursos em infraestrutura, além de ser responsável pela gestão do uso.

4. O programa seria executado em parceria com o programa Novas Alternativas, política habitacional da prefeitura do Rio a ser realizada a partir da reabilitação de antigos sobrados.

5. O relatório apresenta como possibilidade de "Intervenções diretas do Governo Federal" um estudo propondo a viabilidade de produção de mais de 20 mil unidades habitacionais, prevendo a disponibilização de terras públicas para executar empreendimentos atendendo demandas de várias faixas de renda, com recursos do Orçamento Geral da União, do FAR (Fundo de Arrendamento para Residência) e do FGTS, considerando prioridade o financiamento junto ao seu conselho gestor.

6. O acordo é firmado entre a União, por intermédio do Ministério das Cidades, do Ministério da Cultura, do Ministério do Planejamento, Orçamento e Gestão e do Ministério dos Transportes e o município do Rio de Janeiro, com a interveniência da Companhia das Docas do Rio de Janeiro e a participação de BNDES e CEF.

7. Rio de Janeiro, Decreto n. 26.886 de 09/08/2006.

8. No ano seguinte, o Rio recebeu o direito de sediar os Jogos Olímpicos de 2016, e teve início o debate sobre a possibilidade de se transferir à região portuária uma parte dos investimentos para as Olimpíadas, inicialmente previstos para a Barra da Tijuca. O debate sobre a localização da concentração de investimentos para os Jogos Olímpi$\cos$ foi protagonizado pela Prefeitura do Rio, por membros da comunidade de engenheiros e arquitetos e por representantes do setor imobiliário, em especial a ADEMI - Associação de Dirigentes de Empresas do Mercado Imobiliário.

9. Ver http://www1.folha.uol.com.br/poder/2016/05/1772333-cunha-tenta-tirar-da-lava-jato-inquerito-sobre-porto-maravilha.shtml. Acesso em 03/02/2018.

10. As implicações desse modelo são analisadas por mim em Sarue (2016). 
11. A Caixa Econômica Federal é o agente operador do FGTS, responsável pelos recolhimentos e pela gestão administrativa e operacional dos processos. O fundo é gerido por um conselho curador, composto por entidades de trabalhadores, empregadores e pelo governo federal - não há, portanto, representação das unidades subnacionais. Segundo Arretche e Rodden (2004), essa ausência representa um fator importante, uma vez que aumenta a autonomia do governo federal para definir os empréstimos federais.

12. O Prêmio por Opção de Compra (POC) é o mecanismo que estabelece a prioridade na compra dos terrenos prioritários (correspondentes a 60\% do uso de CEPAC) que serão negociados entre as autarquias da União e a Prefeitura do Rio, compensando a diferença entre o valor do CEPAC no leilão (545 reais) e o valor que o FIIPM pagou efetivamente. Trata-se de um instrumento fundamental para compreender a relação estabelecida para a participação do financiador federal na operação.

13. Há uma confluência de projetos políticos com a reeleição do presidente Lula (PT 2006 a 2009) e o anúncio de uma nova candidatura da cidade do Rio de Janeiro para sediar os Jogos Olímpicos de 2016, desta vez com um orçamento mais robusto e apoio decisivo do próprio presidente Lula nas negociações (Silvestre, 2012). Ainda em 2007, o Brasil recebe o direito de sediar a Copa do Mundo da FIFA de 2014, e o Rio de Janeiro é escalado para a partida final. Por fim, nas eleições municipais de 2008, o governo federal apoia a candidatura do prefeito Eduardo Paes (PMDB 2009 a 2012), alinhado à base partidária do governo e ao seu projeto para o país e para a cidade do Rio de Janeiro.

14. O instrumento da Operação Urbana Consorciada prevê a criação de um Conselho Gestor, cuja atribuição é analisar e aprovar os relatórios trimestrais da CDURP quanto à execução dos investimentos previstos, configurando, portanto, um mecanismo de controle transversal do projeto. Cabe, no entanto, o debate a respeito da avaliação de instituições participativas para além do indicador binário de existência ou não (Andrews e Vries, 2007; Spada, 2015), uma vez que o Conselho Gestor é convocado e presidido pela própria CDURP, e os membros da sociedade civil são indicados pelos representantes do poder público, a saber CDURP e duas representações da Prefeitura do Rio. É ilustrativo destacar que dentre os três membros do conselho de representantes da sociedade civil está a Associação de Dirigentes do Mercado Imobiliário do Rio de Janeiro. 


\section{REFERÊNCIAS BIBLIOGRÁFICAS}

ALTSHULER, Alan A; LUBEROFF, David. (2003), Mega-projects: the changing politics of urban public investment. Washington D.C/Cambridge, Brookings Institution Press/Lincoln Institute of Land Policy.

ARRETCHE, Marta; Jonathan RODDEN. (2004), "Política Distributiva na Federação: Estratégias Eleitorais, Barganhas Legislativas e Coalizões de Governo", Dados - Revista de Ciências Sociais, vol. 47, no 4, pp. 549-576.

ARRETCHE, Marta. (2004), Federalismo e políticas sociais no Brasil: problemas de coordenação e autonomia. São Paulo Perspec. [online]. vol.18, no.2 [03-05-2014], pp. 17-26. Disponível em: http:/ /www.scielo.br/dados.

BRENNER, N. (2002), "Cities and the geographies of 'actually existing neoliberalism". In: N. Brenner; N. Theodore (org.) Spaces of neoliberalism. Oxford, Blackwell.

FAINSTEIN, Susan S. (2008), "Mega-projects in New York, London and Amsterdam". International Journal of Urban and Regional Research, vol. 32, no 4, pp.768-785.

CASTELLS, Manuel. (1983), A questão urbana. Rio de Janeiro: Paz e Terra.

FORUM COMUNITARIO DO PORTO. (2011), “Relatório sobre as visitas técnicas realizadas nas comunidades do Morro da Providência e da Pedra Lisa nos dias 23/8 e 7/9/2011 e Parecer Técnico sobre os motivos alegados pela Prefeitura do Rio de Janeiro para a remoção de 832 famílias nessas duas comunidades". [03-05-2014] Disponível em: https://forumcomunitariodoporto.files.wordpress.com/2011/12/relatc3b3rio-morro-da-providc3aancia_final-1.pdf.

GURZA LAVALLE, Adrian; ISUNZA VERA, Ernesto. (2010), “Precisiones conceptuales para el debate contemporáneo sobre la innovación democrática". in: E. Isunza Vera; A. Gurza Lavalle. La innovación democrática en América Latina. Tramas y nudos de la representación, la participación y el control social. México, CIESAS-Universidad Veracruzana, pp. 17-82.

HARVEY, D. (1989) 'From managerialism to entrepreneurialism: the transformation in urban governance in late capitalism' Geografiska Annaler 71-B: 3:17.

HOLYLER, Telma. (2015), “Qual o lugar das cidades no mercado imobiliário?”. Oculum Ensaios PUCCAMP, v. 12, p. 30-50.

LE GALÉS, Patrick. (2000), "Private sectore intrests and urban governance". in: A. Bargansco; P. Le Galés (org.) Cities in contemporary Europe. Cambridge, Cambridge Univestiy Press.

LEVI-FAUR, David. (2005), "The global diffusion of regulatory capitalism". The Annals of the American Academy of Political and Social Science, vol 598, n 1, pp. 12-32.

LOWNDES, Vivien; SKELCHER, Chris. (1998), “The Dynamics of Multi-organizational Partnerships: an Analysis of Changing Modes of Governance". Public Administration, vol. 76, pp. 313-333. doi:10.1111/1467-9299.00103

MARQUES, Eduardo. (2016), “De volta aos capitais para melhor entender as políticas urbanas". Novos Estudos, vol 105, pp. 15. 
MARQUES, Eduardo. (2012), "Governing São Paulo: Urban policies and segregation in a highly unequal metropolis". In Buenos Aires: III World Forum of Sociology.(mimeo).

MINISTÉRIO DAS CIDADES. (2005), "Reabilitação de Centros Urbanos" R. Rolnik; R. Balbim (coord) Secretaria Nacional de Programas Urbanos. Brasília, Ministério das Cidades.

MOLOTCH, Harvey. (1976), "The City as a Growth Machine: Toward a Political Economy of Place". The American Journal of Sociology, Vol. 82, No. 2, pp.309-332.

ONG, Aihwa. (2001), “Worlding cities, or the art of being global”. In A. Roy; A. Ong (org.) Worlding cities. Oxford, Wiley-Blackwell.

PERUZZOTTI, Enrique; SMULOVITZ, Catalina. (2006), "Social Accountability: An Introduction." in: E. Peruzzotti; C. Smulovitz (orgs). Enforcing the Rule of Law: Social Accountability in the New Latin American Democracies. Pittsburgh, University of Pittsburgh Press, pp. 3-27.

RACO, Mike. (2014), “Delivering Flagship Projects in an Era of Regulatory Capitalism: State-led Privatization and London Olympics 2012". International Journal of Urban and Regional Research. vol. 38, no 1, pp. 176-197.

SMF, PGM, IPP/PREFEITURA DA CIDADE DO RIO DE JANEIRO. (2003), Aproveitamento Imobiliário da Região do Porto do Rio. Coleção de Estudos Cariocas. no 20030102.

SARUE, Betina. (2015), Grandes projetos urbanos e a governança das cidades: o caso do Porto Maravilha. Dissertação (Mestrado em Ciência Política), Universidade de São Paulo, São Paulo.

(2016), "Os Capitais Urbanos do Porto Maravilha" Novos Estudos CEBRAP (Impresso), v. 1, pp. 78-97.

SILVESTRE, Gabriel. (2012), An Olympic city in the making. IOC Olympic Studies Centre.

SMOLKA, Martim. (2004). Presentacion. In: Grandes Proyectos Urbanos. Ed. Lungo, Mario. El Salvador: UCA Editores.

STONE, Clarence N. (1993). "Urban regimes and the capacity to govern: A Political Economy Approach". Journal of Urban Affairs. vol. 15, n 1, pp. 1-28.

VAINER, Carlos. (2012), “Grandes proyectos urbanos ¿Qué son y cómo evaluarlos?” in: B. Cuenya; P. Novais; C. Vainer (comp). Grandes proyectos urbanos: miradas críticas sobre la experiencia argentina y brasileña. Buenos Aires, Café de las Ciudades.

DADOS - Revista de Ciências Sociais, Rio de Janeiro, vol. 61, n 3, 2018 
RESUMO

Quando grandes projetos urbanos acontecem? Uma análise a partir do Porto Maravilha no Rio de Janeiro

Os grandes projetos urbanos são uma realidade no mundo, e recentemente também no Brasil. O Rio de Janeiro ensaia desde os anos 1980 a realização de um grande projeto urbano em sua região portuária que apenas agora está sendo implementado, configurando o primeiro projeto de tamanho porte a ser realizado no Brasil. A pergunta que se coloca é: quando, ou em quais condições os grandes projetos urbanos acontecem? A explicação recorrente na literatura associa a sua realização a fatores econômicos centrados na valorização da terra urbana e na competição entre cidades associada a dinâmicas do capitalismo global. Esse artigo busca apresentar um argumento complementar ao debate, que considera além do contexto macroeconômico, as condições institucionais e formais necessárias para viabilizar a implementação de tais projetos. Essa reflexão é feita a partir do debate sobre a governança urbana e de uma análise institucional histórica do caso do Porto Maravilha no Rio de Janeiro. Por fim, o artigo sugere que o tipo de análise apresentado a partir do caso carioca é importante para os estudos sobre grandes projetos urbanos uma vez que o entendimento dos processos institucionais ajuda a entender os impactos do projeto na governança da cidade, sendo que as articulações entre atores influenciam quem ganha o quê no resultado da política.

Palavras-chave: Porto Maravilha; Grandes Projetos Urbanos; Governança Urbana.

\begin{abstract}
When do big urban projects happen? An analysis from Porto Maravilha in Rio de Janeiro

Big urban projects are a reality in the world, and recently also in Brazil. Since the 1980s, Rio de Janeiro has been conducting a major urban project in its port region, which is only now being implemented, which is the first large-scale project to be carried out in Brazil. The question that arises is: when, or under what conditions do large urban projects take place? The recurrent explanation in the literature associates its realization with economic factors centered on the valorization of urban land and the competition between cities associated with the dynamics of global capitalism. This article seeks to present a complementary argument to the debate, which considers in addition to the macroeconomic context, the institutional and formal conditions necessary to
\end{abstract}


enable the implementation of such projects. This reflection is based on the debate on urban governance and a historical institutional analysis of the case of Porto Maravilha in Rio de Janeiro. Finally, the article suggests that the type of analysis presented from the Rio case is important for the studies on large urban projects since the understanding of the institutional processes helps to understand the impacts of the project on the city's governance, between actors influence who wins what in the outcome of the policy.

Keywords: Porto Maravilha; Great Urban Projects; Urban Governance.

RÉSUMÉ

Quand de grands projets urbains se produisent? Une analyse de le Porto Maravilha au Rio de Janeiro

Les grands projets urbains sont une réalité dans le monde et, récemment, au Brésil. Depuis les années 1980, la ville du Rio de Janeiro essaye de mettre en place un grand projet urbain dans sa région portuaire. Il s'agit du premier projet de grande envergure réalisé au Brésil. La question qui se pose est la suivante : quand ont-ils lieu et dans quelles conditions de grands projets urbains? L'explication récurrente dans la littérature associe sa réalisation à des facteurs économiques centrés sur la valorisation des espaces urbains et la compétition entre villes associée à la dynamique du capitalisme mondial. Cet article vise à présenter un argument complémentaire au débat, qui considère au-delà de contexte macroéconomique les conditions institutionnelles et formelles nécessaires pour permettre la mise en œuvre de tels projets. Cette réflexion est fondée au débat sur la gouvernance urbaine et l'analyse institutionnelle historique du cas de Porto Maravilha au Rio de Janeiro. À la fin, l'article suggère que le type d'analyse présenté à partir du cas de Rio est important pour les études sur les grands projets urbains car la compréhension des processus institutionnels aide à comprendre les impacts du projet sur la gouvernance de la ville, entre les acteurs influencent qui gagne quoi dans le résultat de la politique.

Mots-clés: Porto Maravilha; Grands projets urbains; Gouvernance urbaine.

DADOS - Revista de Ciências Sociais, Rio de Janeiro, vol. 61, n² 3, 2018 


\section{Betina Sarue}

\section{RESUMEN}

¿Cuándo ocurren grandes proyectos urbanos? Un análisis desde Porto Maravilla en Río de Janeiro

Los grandes proyectos urbanos son una realidad en el mundo, así como, más recentemente, lo son también en Brasil. Desde los años 1980, la ciudad de Río de Janeiro ensayaba la realización de un gran proyecto urbano en su región portuaria que solamente ahora está siendo implementado - configurando el primer proyecto de éste tamaño realizado en Brasil. La pregunta planteada es: ¿cuándo, o en qué condiciones los grandes proyectos urbanos ocurren? La explicación recurrente en la literatura asocia su realización a factores económicos centrados en la valorización de la tierra urbana y en la dinâmica de concurrencia entre ciudades, concurrencia asociada a dinámicas del capitalismo global. Este artículo busca presentar un argumento complementario al debate, que considera además del contexto macroeconómico, las condiciones institucionales y formales necesarias para viabilizar la implementación de tales proyectos. Esta reflexión se hace a partir del debate sobre la gobernanza urbana y de un análisis institucional histórico del caso del 'Porto Maravilha' en Río de Janeiro. Por último, el artículo sugiere que el tipo de análisis presentado a partir del caso carioca es importante para los estudios sobre grandes proyectos urbanos pues que la compreensión de los procesos institucionales ayuda a entender los impactos del proyecto en la gobernanza de la ciudad, siendo que las articulaciones entre actores influencian quién gana y qué gana en el resultado de la política.

Palavras-clave: 'Porto Maravilha'; grandes proyectos urbanos; gobernanza urbana 


\section{ERRATA}

Na página 581, Onde se lia:

"http://dx.doi.org/10.1590/001152582018154"

Leia-se:

"http://dx.doi.org/10.1590/001152582018168"

DADOS - Revista de Ciências Sociais (2018), vol. 61, no 3: E3-E5 